\title{
OPTIMAL LIME APPLICATION RATES FOR AMELIORATING ACIDIC SOILS AND IMPROVING THE YIELD AND QUALITY OF TOBACCO LEAVES
}

\author{
JIANG, C. ${ }^{1 *}-$ SHEN, J. ${ }^{1}-$ CUI, Q. ${ }^{1}-$ YAN, Y. $^{1}-$ LIU, Y. ${ }^{2}-$ ZU, C..$^{1 *}$ \\ ${ }^{1}$ Tobacco Research Institute, Anhui Academy of Agricultural Sciences, Hefei 230031, China \\ ${ }^{2}$ Anhui provincial tobacco company, Hefei 230071, China \\ (phone: +86-551-6514-8970; fax: +86-551-6514-8991) \\ *Corresponding authors \\ e-mail: chaoqjiang@163.com,lcz2468@sina.com
}

(Received 21 $1^{\text {st }}$ Feb 2020; accepted $2^{\text {nd }}$ Jul 2020)

\begin{abstract}
Liming is a common practice for improving plant growth and yield on acidic soils. However, knowledge is still limited on the effect of liming on tobacco growth and leaf quality planted on acidic soil. In this study, effects of lime $\left(\mathrm{Ca}(\mathrm{OH})_{2}\right)\left(0,0.75,1.5\right.$ and $\left.3 \mathrm{tha}^{-1}\right)$ on soil nutrient status $\left(\mathrm{Ca}^{2+}\right.$ and $\mathrm{Mg}^{2+}$ in particular), growth, nutrient accumulation and quality of flue-cured tobacco was investigated in an acidic soil located in Anhui province, China. The results showed that liming significantly increased soil $\mathrm{pH}$ both 30 days after transplanting and after the harvest of the tobacco. In comparison with CK (no lime application), liming at a rate of $1.5 \mathrm{t} \mathrm{ha}^{-1}$ increased leaf number and leaf dry weight by $15 \%$ and $11 \%$, and enhanced the appearance and smoking quality of cured leaves by $7 \%$ and $9 \%$, respectively. Moreover, liming significantly increased calcium concentration, while decreased nitrogen and magnesium concentration in the cured leaves. The increase in cured leaf quality was attributed to the improvement of chemical composition, particularly the increase in reducing sugar content. Together, our results suggest that $\mathrm{Ca}(\mathrm{OH})_{2}$ application at a rate of $1.5 \mathrm{t} \mathrm{ha}^{-1}$ may alleviate soil acidification and improve yield and quality of flue-cured tobacco in Anhui province, China.
\end{abstract}

Keywords: flue-cured tobacco, soil acidity, calcium, cured leaves quality, soil improvement

\section{Introduction}

Soil acidity is a serious limitation to plant growth and crop production in many regions of the world, since about $40-50 \%$ of the world's arable soils are acidic (Kochian et al., 2015). Extreme acidity in subsoil ( $\mathrm{pH}<5.0)$ limits plant growth and development, which is particularly harmful to root growth and function, and therefore inhibits root water and nutrient acquisition (Lynch and Wojciechowski, 2015; Wang et al., 2017). In less acidic soils ( $\mathrm{pH}>5.0)$, the inhibition of plant growth and yield is more likely due to nutrient deficiencies and toxicities (Karaivazoglou et al., 2007; Hue, 2011). However, these inhibitions for plants may act independently or commonly work together (Karaivazoglou et al., 2007; Kochian et al., 2015). There are various causes for soil acidification, and excess nitrogen $(\mathrm{N})$ fertilizer application has become a major cause in agricultural soils (Guo et al., 2010; Qu et al., 2013; Shaaban et al., 2015). Most of the tobacco (Nicotiana tabacum L.) fields have been affected by acidification due to the intensive cropping and excessive $\mathrm{N}$ fertilizer inputs in Anhui province, China (Zhang et al., 2014; Jiang et al., 2015a). Therefore, it is imperative to ameliorate acid soils and improve the yield and quality of tobacco leaves in these areas. However, optimal measure for ameliorating acid soils in tobacco growing area is still lacking in Anhui province at present. 
Considerable measures have been made to ameliorate acid soils, improve crop yield and quality, such as lime application (Jiang et al., 2015a; Shaaban et al., 2015; Kunhikrishnan et al., 2016), straw retention (Liao et al., 2018), biochar application (Tarin et al., 2019), green manure and biological organic fertilizer application (Deng et al., 2019). Traditionally, surface application of lime materials (including lime, calcite and dolomite) is one of the most common measures to overcome the problems associated with soil acidity (Shaaban et al., 2014; Kunhikrishnan et al., 2016). Previous studies have shown that lime application increases soil $\mathrm{pH}$, improves plant growth and leaf yield of tobacco (Karaivazoglou et al., 2007; Jiang et al., 2015a; Deng et al., 2019). Karaivazoglou et al. (2007) reported that hydrated lime $\left(\mathrm{Ca}(\mathrm{OH})_{2}\right)$ application at a rate of $3 \mathrm{t} \mathrm{ha}^{-1}$ may alleviate soil acidification and increase the yield of flue-cured tobacco in an acid soil ( $\mathrm{pH}$ 5.3), while lead to a decrease in potassium (K) concentration in cured leaves. Moreover, recently, Deng et al. (2019) found that lime application at a rate of $2.25 \mathrm{t} \mathrm{ha}^{-1}$ significantly increased the soil $\mathrm{pH}$ from 5.05 to 5.38 but did not significantly enhanced the yield of flue-cured tobacco. Although the application of lime can increase the soil $\mathrm{pH}$ and alleviate soil acidification, different studies have found diverse conclusions on the effect of lime on the yield and quality of tobacco leaves. The differences in the effect of liming on tobacco are likely to be due to the different type and rate of lime materials, fertilizer application, tobacco varieties and cultivation environment (Karaivazoglou et al., 2007; Jiang et al., 2015a; Deng et al., 2019). Therefore, the suitable type and rate of lime application on tobacco acid soils is limited and needs to be further explored.

Tobacco is an important industrial crop in China, and plays an important economic role for both the national tax income (Zou et al., 2018). Especially, flue-cured tobacco is a main source of many farmers' income, due to the good quality of tobacco leaves in Anhui province (Dong et al., 2015). Soil acidity has always been the main factor limiting tobacco leaves yield and quality, particularly in Anhui province due to the inherent low soil $\mathrm{pH}$ and excessive application of $\mathrm{N}$ fertilizer (Jiang et al., 2015a). Previous studies have shown that the soil $\mathrm{pH}$ for producing high quality tobacco is range from 5.5 to 6.5 (Shao et al., 2012; Jiang et al., 2015a). At present, liming is a common practice for ameliorating acid soils and improve crop yield, and is widely applied to the tobacco acid soils in southern China (Jiang et al., 2015a; Zou et al., 2018). However, research on the effect of liming on plant growth and leaves quality of flue-cured tobacco in the acidic soil is still limited. Therefore, in this study, a pot experiment was carried out to determine the effect of liming on soil nutrient status $\left(\mathrm{Ca}^{2+}\right.$ and $\mathrm{Mg}^{2+}$ in particular), plant growth, nutrient (including micronutrients) accumulation and quality characteristics of tobacco leaves in an acidic soil in Anhui province, China.

\section{Materials and methods}

\section{Experiment site and growth conditions}

The pot experiment was carried out under greenhouse conditions in Chizhou, a major tobacco-producing area of Anhui province, China. The soil was collected from the tobacco field (0-20 cm), with a $\mathrm{pH}$ of $5.35,18.2 \mathrm{~g} \mathrm{~kg}^{-1}$ organic matter, $152.8 \mathrm{mg} \mathrm{kg}^{-1}$ alkali-hydrolyzed $\mathrm{N}, 17.6 \mathrm{mg} \mathrm{kg}^{-1}$ available phosphorus (P) and $168.3 \mathrm{mg} \mathrm{kg}^{-1}$ available $\mathrm{K}$. During the experiment, the tobacco plants were kept in a greenhouse with a $(29 \pm 3)^{\circ} \mathrm{C} /(19 \pm 3)^{\circ} \mathrm{C}$ day/night temperatures, and a $70 \pm 10 \%$ relative humidity. 


\section{Experimental design and Management}

Treatments consisted of four levels of lime $\left(\mathrm{Ca}(\mathrm{OH})_{2}\right)$, namely $0(\mathrm{CK}), 0.75(\mathrm{Ca} 1)$, $1.5(\mathrm{Ca} 2)$ and $3.0 \mathrm{t} \mathrm{ha}^{-1} \mathrm{Ca}(\mathrm{OH})_{2}(\mathrm{Ca} 3)$ in the experiment. In tobacco growing area of Chizhou, the tobacco plants were cultured in $1.2 \mathrm{~m}$ spaced rows with $0.5 \mathrm{~m}$ distance. Therefore, it should add $0,6.67,13.33,26.67 \mathrm{~g} \mathrm{Ca}(\mathrm{OH})_{2}$ per pot cultivating one tobacco plant for the $\mathrm{CK}, \mathrm{Ca} 1, \mathrm{Ca} 2$ and $\mathrm{Ca} 3$, respectively. The pot was $35 \mathrm{~cm}$ in diameter and $28 \mathrm{~cm}$ in height, containing $20 \mathrm{~kg}$ of air-dried and $2 \mathrm{~mm}$-sieved soil. The $\mathrm{Ca}(\mathrm{OH})_{2}(\mathrm{AR})$ powder and all the fertilizers needed for the flue-cured tobacco were applied as basal and fertilizer and mixed thoroughly with soil in the pot two days before the seedlings transplanting. Fertilizers were use as Jiang et al. (2015b).

Flue-cured tobacco (Nicotiana tabacum L., cv. Yunyan 87) seedlings were transplanted to individual pots when they were about $12 \mathrm{~cm}$ in height. The pots were placed neatly according to the plant spacing of $120 \mathrm{~cm}$ and the row spacing of $50 \mathrm{~cm}$. Each treatment was replicated three times and each replicate included six plants (i.e. 18 plants per treatment). During the period of 60-65 days after transplanting, when approximately $50 \%$ of the plants in each plot were at full bloom, they were topped (Karaivazoglou et al., 2007). Tobacco leaves were harvested five times by hand starting 70-80 days after transplanting. Three or five leaves were removed by hand at 7- or 8day intervals when the leaves were mature and turn yellow from bottom to top, and cured immediately in a flue-curing barn. Photos of the experimental culture were shown in Figure 1.
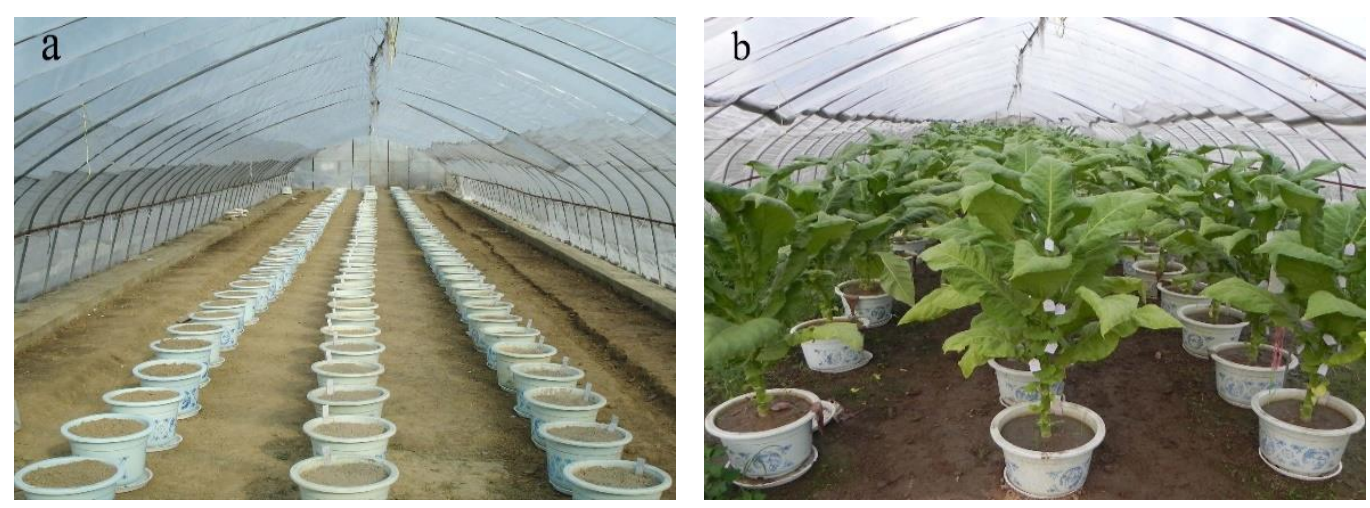

Figure 1. Photos of the experimental culture before the seedlings transplanting (a) and 90 days after transplanting $(b)$

\section{Sample collection and determination}

Plant height, leaf number and stem diameter were measured after topping of the tobacco plant. The plants were divided into leaves, stems and roots, and dry weights were measured after being dried to constant weight at $65^{\circ} \mathrm{C}$.

The cured leaves (from nodes 8 to 12) were used to determine appearance quality, smoking quality and the concentrations of elements. Both the appearance quality and the smoking quality of the leaves were graded using a scale from 1 to 10 (quality index) (Karaivazoglou et al., 2007). The appearance quality included maturity, structure, status, oil, color and chroma of the cured leaf. The smoking quality included aroma quality and quantity, fineness, roundness, hygroscopicity and uniformity of the cured leaf. For elements analysis, the leaves samples were dried to constant weight at $65{ }^{\circ} \mathrm{C}$, 
and milled into powder. The $\mathrm{N}$ concentration was analyzed according to the method of Karaivazoglou et al. (2007). The $\mathrm{K}$, calcium (Ca) and magnesium ( $\mathrm{Mg}$ ) concentration were determined according to the method of Shao et al. (2012) and Tang et al. (2013).

Before the experiment, soils were collected to determine the basic fertility. At 30 days after transplanting, soils of each treatment were sampled for determining the soil $\mathrm{pH}$. After harvest, soil samples were collected from each treatment for $\mathrm{pH}$, exchangeable $\mathrm{Ca}$ and exchangeable $\mathrm{Mg}$ analysis. Soil $\mathrm{pH}$, organic matter, alkalihydrolyzed $\mathrm{N}$, available $\mathrm{P}$, available $\mathrm{K}$, exchangeable $\mathrm{Ca}$ and exchangeable $\mathrm{Mg}$ were determined according to the method of Shao et al. (2012) and Tang et al. (2013).

\section{Statistical analysis}

Statistical analyses were performed using one-way ANOVA with SPSS 19.0 (SPSS Inc., Chicago, IL, USA). The treatments were compared by the method of least significance difference at $P<0.05$.

\section{Results}

\section{Effect of liming on plant height, leaf number, and dry weight of tobacco plant}

As showed in Table 1, Ca application had a significant effect on plant height, leaf number, and dry weight of the tobacco plant. The plant height and leaf number of $\mathrm{Ca} 2$ were significantly increased by $9 \%$ and $15 \%$ compared with the CK, respectively, but no significant difference was found between the $\mathrm{Ca} 2$ and $\mathrm{Ca} 3$ treatments. However, the stem diameter of tobacco plant was not significantly affected by $\mathrm{Ca}$ application at the rate of 0.75 to $3.0 \mathrm{t} \mathrm{ha}^{-1} \mathrm{Ca}(\mathrm{OH})_{2}$. The leaf and total dry weight of the tobacco plant was highest in $\mathrm{Ca} 2$ treatment, which was $11 \%$ and $17 \%$ higher than that of the $\mathrm{CK}$, respectively. Similarly, $\mathrm{Ca} 2$ treatment achieved the highest root and leaf dry weight among all treatments. The root/shoot ratio of $\mathrm{Ca} 2$ treatment was significantly higher than that of the $\mathrm{CK}, \mathrm{Ca} 1$ and $\mathrm{Ca} 3$ treatments.

Table 1. Effects of $\mathrm{Ca}(\mathrm{OH})_{2}$ application on plant height, leaf number, stem diameter and dry weight of tobacco plant

\begin{tabular}{c|c|c|c|c|c|c|c}
\hline \multirow{2}{*}{ Treatments } & \multirow{2}{*}{$\begin{array}{c}\text { Plant } \\
\text { height }\end{array}$} & \multirow{2}{*}{$\begin{array}{c}\text { Number of } \\
\text { leaves per plant }\end{array}$} & \multirow{2}{*}{$\begin{array}{c}\text { Stem } \\
\text { diameter }\end{array}$} & \multicolumn{2}{|c|}{ Dry weight $(\mathbf{g}$ plant } & \multirow{2}{*}{ Root/shoot } \\
\cline { 5 - 6 } & $(\mathbf{c m})$ & Root & Leaves & Total & \\
\hline $\mathrm{CK}$ & $88.0 \mathrm{~b}$ & $20.3 \mathrm{~b}$ & $83.0 \mathrm{a}$ & $22.1 \mathrm{~b}$ & $72.0 \mathrm{~b}$ & $117.4 \mathrm{~b}$ & $0.23 \mathrm{~b}$ \\
$\mathrm{Ca} 1$ & $90.3 \mathrm{~b}$ & $21.0 \mathrm{~b}$ & $84.7 \mathrm{a}$ & $22.8 \mathrm{~b}$ & $73.9 \mathrm{~b}$ & $121.0 \mathrm{~b}$ & $0.23 \mathrm{~b}$ \\
$\mathrm{Ca} 2$ & $95.7 \mathrm{a}$ & $23.3 \mathrm{a}$ & $88.7 \mathrm{a}$ & $29.3 \mathrm{a}$ & $79.6 \mathrm{a}$ & $136.9 \mathrm{a}$ & $0.27 \mathrm{a}$ \\
$\mathrm{Ca} 3$ & $92.0 \mathrm{ab}$ & $21.7 \mathrm{ab}$ & $86.7 \mathrm{a}$ & $25.0 \mathrm{~b}$ & $75.6 \mathrm{ab}$ & $126.7 \mathrm{ab}$ & $0.25 \mathrm{~b}$ \\
\hline
\end{tabular}

Means within a column that have different letters are significantly different from each other at $P<0.05$. The CK, Ca1, Ca2 and $\mathrm{Ca} 3$ are respectively $0,0.75,1.5$ and $3.0 \mathrm{tha}^{-1} \mathrm{Ca}(\mathrm{OH})_{2}$

\section{Effect of liming on concentrations of elements in tobacco leaf}

As showed in Table 2, lime application significantly decreased the $\mathrm{N}$ concentration in tobacco leaves. However, liming did not significantly affect the $\mathrm{K}$ concentration in tobacco leaves. The $\mathrm{Ca}$ concentration in leaves of $\mathrm{Ca} 1, \mathrm{Ca} 2$ and $\mathrm{Ca} 3$ was significantly increased by $43 \%, 59 \%$ and $109 \%$ than that of the control without $\mathrm{Ca}$, respectively. The 
Ca concentration in leaves was significantly increased with an increased Ca application rate. However, the $\mathrm{Mg}$ concentration in leaves declined with an increase of the $\mathrm{Ca}$ application rate, and the $\mathrm{Ca} 2$ and $\mathrm{Ca} 3$ treatments resulted in $23 \%$ and $30 \%$ decrease of $\mathrm{Mg}$ concentration in leaves compared with the $\mathrm{CK}$, respectively. Similarly, $\mathrm{Ca}$ application also decreased the $\mathrm{P}$ concentration in leaves. Under the $\mathrm{Ca} 3$ treatment, the $\mathrm{P}$ concentration in leaves was reduced by $15 \%$ than that of the CK.

Table 2. Effect of $\mathrm{Ca}(\mathrm{OH})_{2}$ application on concentrations $\left(\mathrm{g} \mathrm{kg}^{-1} \mathrm{DW}\right)$ of $\mathrm{N}, \mathrm{P}, \mathrm{K}, \mathrm{Ca}$ and $\mathrm{Mg}$ in leaves of tobacco plant

\begin{tabular}{c|c|c|c|c|c}
\hline Treatments & $\mathbf{N}$ & $\mathbf{P}$ & $\mathbf{K}$ & $\mathbf{C a}$ & $\mathbf{M g}$ \\
\hline $\mathrm{CK}$ & $30.9 \mathrm{a}$ & $5.29 \mathrm{a}$ & $19.8 \mathrm{a}$ & $30.2 \mathrm{c}$ & $4.18 \mathrm{a}$ \\
$\mathrm{Ca} 1$ & $27.0 \mathrm{~b}$ & $4.75 \mathrm{ab}$ & $21.4 \mathrm{a}$ & $43.3 \mathrm{~b}$ & $4.05 \mathrm{a}$ \\
$\mathrm{Ca} 2$ & $27.3 \mathrm{~b}$ & $4.91 \mathrm{ab}$ & $21.2 \mathrm{a}$ & $47.9 \mathrm{~b}$ & $3.23 \mathrm{~b}$ \\
$\mathrm{Ca} 3$ & $28.1 \mathrm{~b}$ & $4.48 \mathrm{~b}$ & $20.3 \mathrm{a}$ & $63.2 \mathrm{a}$ & $2.92 \mathrm{~b}$ \\
\hline
\end{tabular}

Means within a column that have different letters are significantly different from each other at $P<0.05$. The CK, Ca1, Ca2 and $\mathrm{Ca} 3$ are respectively $0,0.75,1.5$ and $3.0 \mathrm{t} \mathrm{ha}^{-1} \mathrm{Ca}(\mathrm{OH})_{2}$

The effect of $\mathrm{Ca}$ application on concentrations of microelements in tobacco leaf was showed in Table 3. The application of $\mathrm{Ca}$ resulted in a reduction of iron (Fe), manganese $(\mathrm{Mn})$, copper $(\mathrm{Cu})$ and zinc $(\mathrm{Zn})$ in tobacco leaf. Compared with the $\mathrm{CK}$, the $\mathrm{Ca} 3$ treatment significantly decreased $\mathrm{Fe}, \mathrm{Mn}, \mathrm{Cu}$ and $\mathrm{Zn}$ in tobacco leaf by $52 \%, 71 \%$, $45 \%$ and $51 \%$, respectively; and the $\mathrm{Ca} 2$ treatment significantly decreased Fe, $\mathrm{Mn}$ and $\mathrm{Zn}$ in tobacco leaf by $34 \%, 37 \%$ and $29 \%$, respectively. In contrast, Ca application significantly increased the chloride $(\mathrm{Cl})$ concentration in tobacco leaf compared with the $\mathrm{CK}$, and the $\mathrm{Cl}$ concentration in leaves was increased with the increase of $\mathrm{Ca}$ application rate.

Table 3. Effect of $\mathrm{Ca}(\mathrm{OH})_{2}$ application on concentration of micronutrients in leaves of tobacco plant

\begin{tabular}{c|c|c|c|c|c}
\hline Treatments & $\begin{array}{c}\mathbf{F e} \\
\left(\mathrm{mg} \mathrm{kg}^{-1}\right)\end{array}$ & $\begin{array}{c}\mathbf{M n} \\
\left(\mathrm{mg} \mathrm{kg}^{-1}\right)\end{array}$ & $\begin{array}{c}\mathbf{C u} \\
\left(\mathrm{mg} \mathrm{kg}^{-1}\right)\end{array}$ & $\begin{array}{c}\mathbf{Z n} \\
\left(\mathrm{mg} \mathrm{kg}^{-1}\right)\end{array}$ & $\begin{array}{c}\mathbf{C l} \\
\left(\mathrm{g} \mathrm{kg}^{-1}\right)\end{array}$ \\
\hline $\mathrm{CK}$ & $530.7 \mathrm{a}$ & $749.1 \mathrm{a}$ & $12.10 \mathrm{a}$ & $109.6 \mathrm{a}$ & $3.32 \mathrm{c}$ \\
$\mathrm{Ca} 1$ & $447.0 \mathrm{ab}$ & $659.7 \mathrm{a}$ & $10.84 \mathrm{a}$ & $98.2 \mathrm{ab}$ & $4.25 \mathrm{~b}$ \\
$\mathrm{Ca} 2$ & $350.5 \mathrm{bc}$ & $473.3 \mathrm{~b}$ & $9.70 \mathrm{ab}$ & $77.9 \mathrm{bc}$ & $4.67 \mathrm{ab}$ \\
$\mathrm{Ca} 3$ & $258.5 \mathrm{c}$ & $215.1 \mathrm{c}$ & $6.60 \mathrm{~b}$ & $53.7 \mathrm{c}$ & $4.91 \mathrm{a}$ \\
\hline
\end{tabular}

Means within a column that have different letters are significantly different from each other at $P<0.05$. The CK, Ca1, Ca2 and Ca3 are respectively $0,0.75,1.5$ and $3.0 \mathrm{t} \mathrm{ha}^{-1} \mathrm{Ca}(\mathrm{OH})_{2}$

\section{Effect of liming on appearance and smoking quality of cured leaf}

The application of $\mathrm{Ca}$ had a significant effect on the appearance and smoking quality of cured leaves (Fig. 2). Both the appearance and smoking quality of cured leaves were highest in $\mathrm{Ca} 2$, and increased by $7 \%$ and $9 \%$ compared with the control, respectively. However, there was no significant difference was observed between treatments $\mathrm{Ca} 1$ and $\mathrm{Ca} 2$ in the appearance and smoking quality of cured leaves. Moreover, $\mathrm{Ca} 3$ treatment 
did not significantly affect the smoking quality of cured leaves or even showed a declining trend in appearance quality compared with the control.
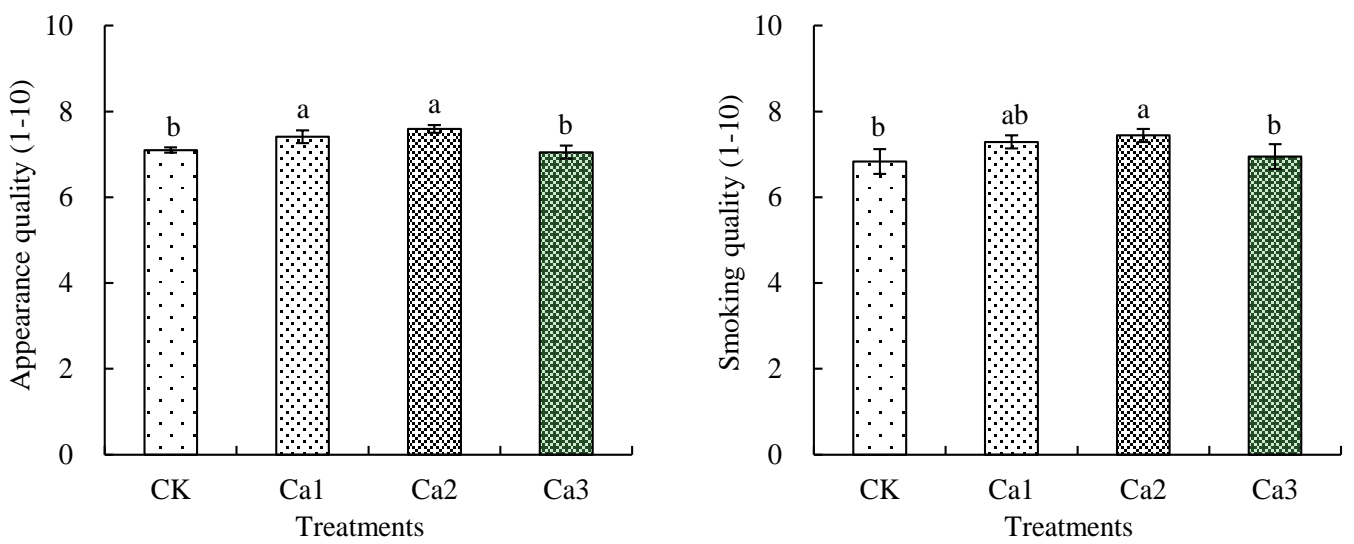

Figure 2. Effect of $\mathrm{Ca}(\mathrm{OH})_{2}$ application on appearance and smoking quality of tobacco leaves. The CK, Ca1, Ca2 and Ca3 are respectively 0, 0.75, 1.5 and 3.0 t ha ${ }^{-1} \mathrm{Ca}(\mathrm{OH})_{2}$. The error bars indicate standard error. Columns with different letters indicate significant difference among different treatments $(P<0.05)$

\section{Effect of liming on soil $\mathrm{pH}$ and calcium and magnesium content}

As showed in Figure 3, Ca application significantly increased the soil pH 30 days after transplanting and after harvest. Compared with the $\mathrm{CK}$, the soil $\mathrm{pH}$ was significantly increased by $0.30,0.61$ and 0.81 units in $\mathrm{Ca} 1, \mathrm{Ca} 2$ and $\mathrm{Ca} 3$ treatments 30 days after transplanting, respectively; and by $0.24,0.36$ and 0.73 units, respectively. After harvest, the highest soil $\mathrm{pH}$ was found in $\mathrm{Ca} 3$ treatment (6.02), which was significantly higher than the other treatments; however, there was no significant difference in soil $\mathrm{pH}$ between the $\mathrm{CK}$ and $\mathrm{Ca} 1$ treatments.
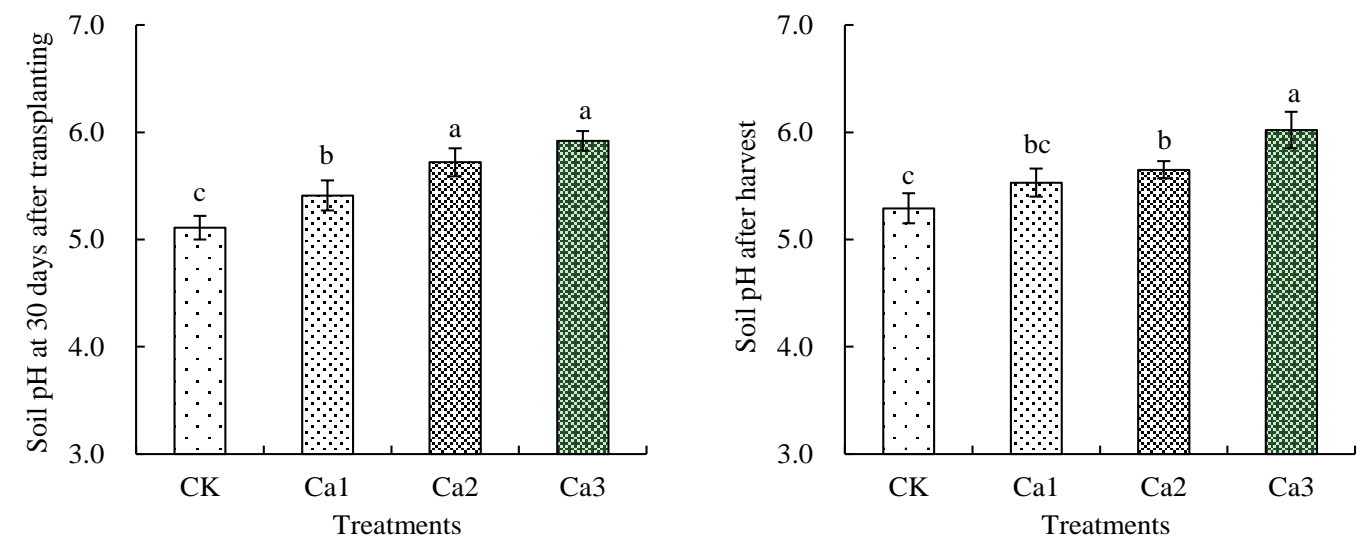

Figure 3. Effect of $\mathrm{Ca}(\mathrm{OH})_{2}$ application on soil $\mathrm{pH}$. The $\mathrm{CK}, \mathrm{Cal}, \mathrm{Ca} 2$ and $\mathrm{Ca} 3$ are respectively 0, 0.75, 1.5 and $3.0 \mathrm{tha}^{-1} \mathrm{Ca}(\mathrm{OH})_{2}$. The error bars indicate standard error. Columns with different letters indicate significant difference among different treatments $(P<0.05)$ 
Furthermore, the effect of liming on soil exchangeable $\mathrm{Ca}^{2+}$ and $\mathrm{Mg}^{2+}$ was investigated. The exchangeable $\mathrm{Ca}$ content of soil was increased with an increased $\mathrm{Ca}$ application rate (Fig. 4 and Fig. 5). Compared with the $\mathrm{CK}$ treatment, $\mathrm{Ca} 2$ and $\mathrm{Ca} 3$ significantly increased the exchangeable Ca content of soil by $16 \%, 100 \%$ and $147 \%$, respectively. In contrast, the exchangeable $\mathrm{Mg}$ content of soil was decreased with the increase of $\mathrm{Ca}$ application rate. The $\mathrm{Ca} 2$ and $\mathrm{Ca} 3$ treatments resulted in $24 \%$ and $29 \%$ decrease in exchangeable $\mathrm{Mg}$ content of soil compared with the $\mathrm{CK}$, respectively. However, there was no significant difference in both the exchangeable $\mathrm{Ca}$ and $\mathrm{Mg}$ content of soil between the CK and Ca1 treatment.
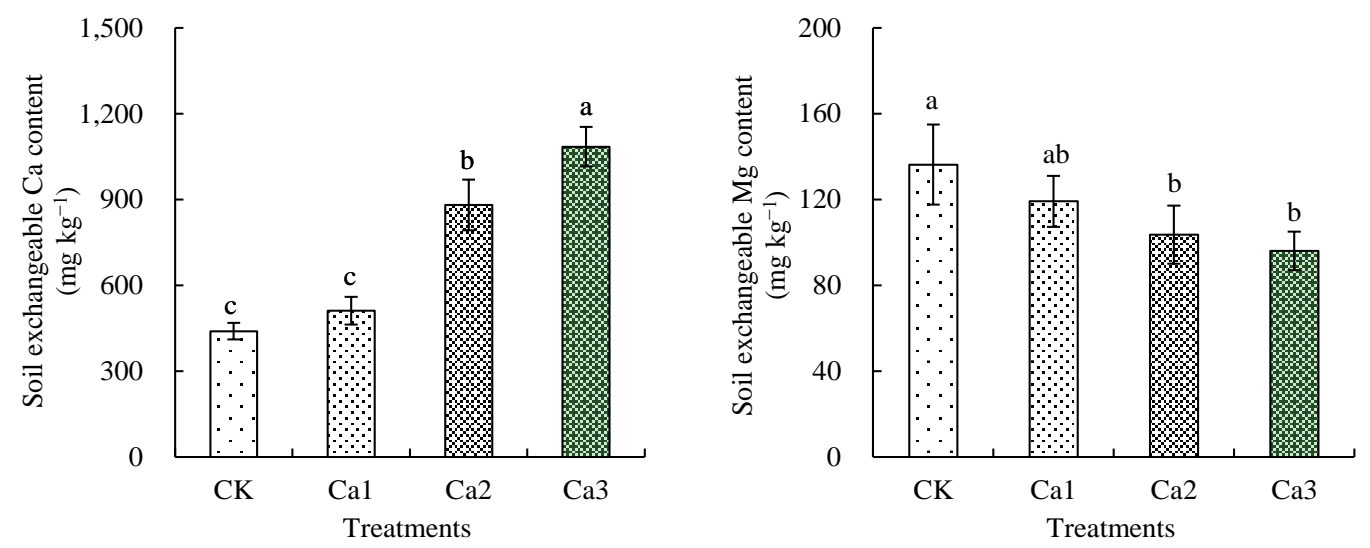

Figure 4. Effect of $\mathrm{Ca}(\mathrm{OH})_{2}$ application on exchangeable $\mathrm{Ca}$ and $\mathrm{Mg}$ content of soil. The $\mathrm{CK}$, $\mathrm{Cal}, \mathrm{Ca} 2$ and $\mathrm{Ca} 3$ are respectively $0,0.75,1.5$ and $3.0 \mathrm{t} \mathrm{ha} \mathrm{C}^{-1} \mathrm{Ca}(\mathrm{OH})_{2}$. The error bars indicate standard error. Columns with different letters indicate significant difference among different treatments $(P<0.05)$
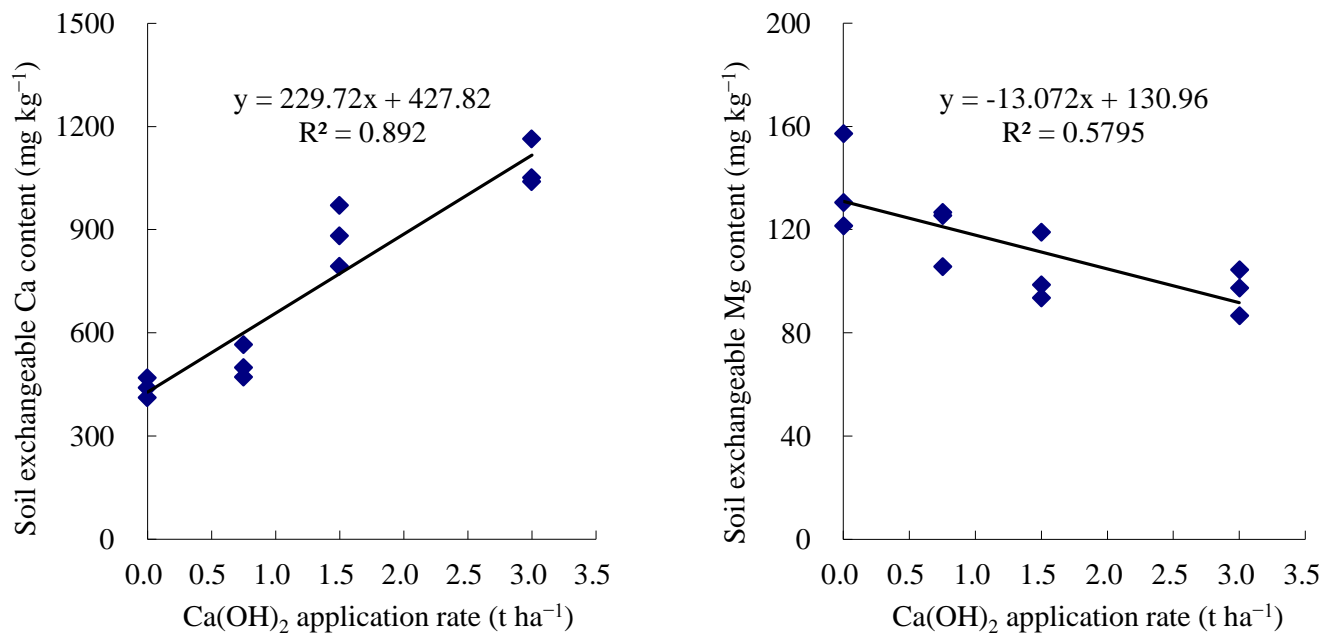

Figure 5. Relationship between $\mathrm{Ca}(\mathrm{OH})_{2}$ application rate and soil exchangeable cations ( $\mathrm{Ca}$ and $\mathrm{Mg}$ ) content. Data were the means of three replicates 


\section{Discussion}

Liming is a common practice to alleviate soil acidification and improve crop yield in acidic soils (Crusciol et al., 2016; Holland et al., 2018; Liao et al., 2018). In this study, lime $\left(\mathrm{Ca}(\mathrm{OH})_{2}\right)$ application significantly enhanced leaves plant dry weight of flue-cured tobacco on an acidic soil, which is consistent with previous studies in Virginia tobacco (Karaivazoglou et al., 2007), rice (Jiang et al., 2018), and sugarcane (Pang et al., 2019). The improvement plant growth and dry weight in flue-cured tobacco were associated with the increase in plant height and higher leaf number per plant (Table 1), in agreement with the findings of Karaivazoglou et al. (2007) in flue-cured tobacco. Crop yield was increased by liming in acidic soils was mainly due to increase soil $\mathrm{pH}$ and improving the availability of soil nutrients (López-Lefebre et al., 2001; Zeng et al., 2017; Liu et al., 2018). In this study, soil $\mathrm{pH}$ was significantly increased by 0.36 units in the treatment received $1.5 \mathrm{t} \mathrm{ha}^{-1}$ in comparison to without liming (pH 5.29) (Fig. 3), and the plant total dry weight was increased by $17 \%$ (Table 1). Although numerous studies have shown that liming significantly increased crop yield on acidic soils, continuous or excessive application of lime also lead to a significant decrease in crop yield (Zhang and Zheng, 1987; Zeng et al., 2017). The present results showed that the application of lime at a relatively high rate $\left(3.0 \mathrm{t} \mathrm{ha}^{-1}\right)$ did not significantly affect the plant total dry weight, plant height and leaf number per plant (Table 1), in contrast to previous studies (Karaivazoglou et al., 2007). The optimal rate of lime to improve acidic soil and enhance crop yield was quite various in different studies may be due to rainfall and soil water content as these factors affect the rate and extent of lime dissolution and subsequent plant response (Liu et al., 2004; Hu et al., 2016; Zhang et al., 2019). We recognize that more field trials are needed to provide more evidences that liming can improve the growth and yield of flue-cured tobacco. The present study provides clear evidence that the optimal rate of liming was $1.5 \mathrm{t} \mathrm{ha}^{-1}$ for flue-cured tobacco growth and development in an acidic soil with a $\mathrm{pH}$ below 5.5.

Furthermore, appropriate rate $\left(1.5 \mathrm{t} \mathrm{ha}^{-1}\right)$ of lime application on acidic soil significantly improved the appearance and smoking quality of tobacco leaves (Fig. 2). The results are in agreement with Karaivazoglou et al. (2007), reported that liming significantly increased the quality index of cured leaves of Virginia tobacco. Also, many studies have shown that lime application increased the quality of tobacco cured leaves (Tang and Xiong, 2003; Zhu et al., 2016a,b; Deng et al., 2019). In relevant research, Zhu et al. (2016b) reported that tobacco plant growth and leaf quality were significantly improved at the lime application rate of $1.5 \mathrm{t} \mathrm{ha}^{-1}$ for alleviating acidity of yellow soil ( $\mathrm{pH}$ 5.0). Moreover, the physical and chemical properties and the smoking quality of tobacco leaves were increased by lime application rate of $2.25 \mathrm{t} \mathrm{ha}^{-1}$ for the sustainable remediation of acid soil (Deng et al., 2019). One possible explanation for the improvement in smoking quality of tobacco leaves would be that liming of acid soils improved chemical composition availabilities of the cured leaves, particularly enhanced reducing sugar content in cured leaves (Zhu et al., 2016a; Deng et al., 2019). We also found that the reducing sugar content of cured leaves was increased at the lime application rate of 0.75 and $1.5 \mathrm{t} \mathrm{ha}^{-1}$ (data not shown). However, there are still unclear how the lime application affected the sugar accumulation in tobacco leaves. Therefore, more attention should be paid on the relationship of Ca concentration and sugar content in tobacco cured leaves.

As expected, leaf $\mathrm{Ca}$ concentration increased significantly with increasing $\mathrm{Ca}(\mathrm{OH})_{2}$ application rates in the soil. These results are in agreement with those reported by 
Karaivazoglou et al. (2007), who reported that leaf Ca concentration was significantly increased by $10 \%$, as $\mathrm{Ca}(\mathrm{OH})_{2}$ application increased from 0 to $3 \mathrm{t} \mathrm{ha}^{-1}$. López-Lefebre et al. (2001) also found that the $\mathrm{Ca}$ concentration in the leaves accumulated progressively with increasing $\mathrm{CaCl}_{2}$ application in the culture medium. The increase in leaf $\mathrm{Ca}$ was mainly due to the increase in soil exchangeable $\mathrm{Ca}$ in the $\mathrm{Ca}(\mathrm{OH})_{2}$ application treatments, because the $\mathrm{Ca}$ uptake in tobacco leaf was significant positive correlation with the content of soil available Ca (Zou and Xiong, 2010; Liu et al., 2017). However, excessive Ca concentration may result in a decline in the sensory quality of tobacco cured leaves (Duan et al., 2010; Dai et al., 2017). We found that the smoking quality of cured leaf of the $\mathrm{Ca} 3$ was significantly lower than that of the $\mathrm{Ca} 1$ and $\mathrm{Ca} 2$ (Fig. 2), which may probably due to the $\mathrm{Ca} 3$ greatly increased the Ca concentration of tobacco leaves (Table 2). Many studies have shown that $\mathrm{Ca}$ concentration of high quality tobacco leaves should be less than $35 \mathrm{~g} \mathrm{~kg}^{-1}$ (Hu et al., 1997; Duan et al., 2010). Therefore, a suitable concentration of $\mathrm{Ca}$ in tobacco leaves must be considered for determining the optimal lime dosage for improving acidic soil.

In contrast, increasing the $\mathrm{Ca}(\mathrm{OH})_{2}$ application rates diminished the leaf $\mathrm{Mg}$ concentration, the lowest concentration of $\mathrm{Mg}$ being found in $\mathrm{Ca} 3$ treatment, with a $30 \%$ decrease in comparison with the CK (Table 2). In agreement with our findings, López-Lefebre et al. (2001) reported that increasing $\mathrm{CaCl}$ application in the culture medium caused a gradual decline in $\mathrm{Mg}$ concentration in the roots and leaves. Duan et al. (2010) indicated that $\mathrm{Mg}$ concentration in leaf was increased by decreasing the soil $\mathrm{Ca}^{2+} / \mathrm{Mg}^{2+}$, i.e. an increase in soil exchangeable $\mathrm{Ca}$ will lead to the decrease of $\mathrm{Mg}$ concentration in tobacco leaves. In this study, the soil $\mathrm{Ca}^{2+} / \mathrm{Mg}^{2+}$ was significantly increased from on average 3.2 to 11.3 (Fig. 4), and the $\mathrm{Mg}$ concentration in leaf was decreased from 4.18 to $2.92 \mathrm{~g} \mathrm{~kg}^{-1}$ (Table 2) by applying $3.0 \mathrm{t} \mathrm{ha}^{-1} \mathrm{Ca}(\mathrm{OH})_{2}$ in acid soil. However, Karaivazoglou et al. (2007) found that Mg concentration of cured leaves was not significantly affected by $\mathrm{Ca}(\mathrm{OH})_{2}$ application in acid soil. It was reported that the $\mathrm{Mg}$ concentration of superior tobacco leaves usually ranged from 4 to $15 \mathrm{~g} \mathrm{~kg}^{-1}$, and low $\mathrm{Mg}$ concentration would reduce the quality of cured leaves (Xu et al., 2007; Duan et al., 2010). Therefore, the application of lime should increase the soil $\mathrm{pH}$ in acidic soil without reducing the $\mathrm{Mg}$ concentration to ensure the quality of tobacco leaves.

In addition, many studies have shown that $\mathrm{K}$ concentration is one of the most important indexes to evaluate the quality of tobacco leaves, and the $\mathrm{K}$ concentration of good quality tobacco leaves should be up to $25 \mathrm{~g} \mathrm{~kg}^{-1}$ (Wei et al., 2011; Li et al., 2015; Yan et al., 2018). Karaivazoglou et al. (2007) reported that leaf K concentration was significantly decreased by $10 \%$ and $12 \%$ under the application of 1.5 and $3.0 \mathrm{t} \mathrm{ha}^{-1}$ $\mathrm{Ca}(\mathrm{OH})_{2}$ in flue-cured tobacco. In contrast, both Li et al. (2005) and Wei et al. (2011) found that calcium application improved the $\mathrm{K}$ uptake and increased the $\mathrm{K}$ concentration in flue-cured tobacco leaves. In this study, the leaf $\mathrm{K}$ concentration was numerically higher in the lime application treatments than in the control, but was not statistically significant (Table 2). The $\mathrm{K}$ concentration in tobacco leaves increased by lime application was probably due to $\mathrm{Ca}$ can have a direct, positive effect on $\mathrm{K}$ uptake, promoting the accumulation of K by the tobacco plant (Qiang et al., 2001; Wei et al., 2011). However, the positive effect of lime on $\mathrm{K}$ accumulation in tobacco leaves was not clearly reflected in the present study. Thus, further experiments, especially longterm field trials are needed to confirm whether and how the effect of liming on $\mathrm{K}$ accumulation in tobacco leaves. 


\section{Conclusion}

The experiment explored the effect of liming on soil nutrient status, plant growth, nutrients accumulation and quality characteristics of flue-cured tobacco in an acid soil. The results confirmed that positive response of liming on ameliorating acidic soils, improving plant growth and yield. We found that liming enhances the growth and yield of flue-cured tobacco in an acid soil, and the appearance and smoking quality of cured leaves was improved with lime application at a rate of $1.5 \mathrm{t} \mathrm{Ca}(\mathrm{OH})_{2} \mathrm{ha}^{-1}$. Furthermore, the soil $\mathrm{pH}$ was significantly increased from 5.29 to 5.65 in the treatment received $1.5 \mathrm{t}$ $\mathrm{Ca}(\mathrm{OH})_{2} \mathrm{ha}^{-1}$. Although long-term field experiments are needed to investigate the influence of liming on $\mathrm{K}$ concentraion and quality in tobacco cured leaves, our results suggest that application of $\mathrm{Ca}(\mathrm{OH})_{2}$ at a rate of $1.5 \mathrm{t} \mathrm{ha}^{-1}$ may alleviate soil acidity, improve yield and quality of flue-cured tobacco, especially in soil with a pH below 5.5.

Acknowledgements. This study was funded by the Discipline Team Project of Anhui Academy of Agricultural Sciences (No. 2019YL039 and No. 2020YL059), the Science and Technology Project of Anhui Province Tobacco Company (No. 20170551022 and No. 20180551009).

\section{REFERENCES}

[1] Crusciol, C. A., Artigiani, A. C., Arf, O., Carmeis Filho, A. C., Soratto, R. P., Nascente, A. S., Alvarez, R. C. (2016): Soil fertility, plant nutrition, and grain yield of upland rice affected by surface application of lime, silicate, and phosphogypsum in a tropical no-till system. - Catena 137: 87-99.

[2] Dai, H., Zhang, S., Wang, A., Zhou, H., Liang, T., Song, J., Zhang, Y., Yin, Q. (2017): Contents of some mineral nutrient elements in flue-cured tobacco and their relationship with sensory quality. - Tobacco Science \& Technology 50(4): 1-9.

[3] Deng, X., Huang, J., Yang, L., Chen, J., Li, Y., Tian, M., Zhou, M., Tian, F., Zhang, M. (2019): The synergistic effect of lime, green manure and bio-organic fertilizer on restoration of acid field and improvement of tobacco production efficiency. - Journal of Plant Nutrition and Fertilizers 25(9): 1577-1587.

[4] Dong, J., Wang, X., Zhang, L. (2015): Development and management of Anhui tobacco with high quality and good characteristics. - Chinese Tobacco Science 36(4): 106-109.

[5] Duan, Z., Zheng, B., Lu, Y., Hu, W., Liu, D., Yin, S. (2010): Effects of $\mathrm{Ca}^{2+} / \mathrm{Mg}^{2+}$ regulation on $\mathrm{Mg}, \mathrm{K}$ and $\mathrm{Ca}$ uptake in the different parts of flue-cured tobacco leaf. - Soil and Fertilizer Sciences in China 5: 61-65.

[6] Guo, J., Liu, X., Zhang, Y., Shen, J., Han, W., Zhang, W., Christie, P., Goulding, K., Vitousek, P., Zhang, F. (2010): Significant acidification in major Chinese croplands. Science 327: 1008-1010.

[7] Holland, J. E., Bennett, A. E., Newton, A. C., White, P. J., McKenzie, B. M., George, T. S., Pakeman, R. J., Bailey, J. S., Fornara, D. A., Hayes, R. C. (2018): Liming impacts on soils, crops and biodiversity in the UK: A review. - Science of the Total Environment 610: 316-332.

[8] Hu, G., Zhao, Y., Cao, Z., Zhao, X., Zhao, Z., Chen, J., Zhang, X., Zhou, X., Li, Z. (1997): The evaluation of the chemical elements and some organic components in fluecured leaf tobacco from the main tobacco production provinces of China. - Acta Tabacaria Sinica 3(1): 36-44.

[9] Hu, M., Xiang, Y., Lu, J. (2016): Effects of lime application rates on soil acidity and barley seeding growth in acidic soils. - Scientia Agricultura Sinica 49(20): 3896-3903.

[10] Hue, N. V. (2011): Alleviating soil acidity with crop residues. - Soil Science 176: 543 549. 
[11] Jiang, C., Dong, J., Xu, J., Shen, J., Xue, B., Zu, C. (2015a): Effects of soil amendment on soil $\mathrm{pH}$, plant growth and heavy metal accumulation of flue-cured tobacco in acid soil. - Soils 47(1): 171-176.

[12] Jiang, C., Zu, C., Shen, J., Shao, F., Li, T. (2015b): Effects of selenium on the growth and photosynthetic characteristics of flue-cured tobacco (Nicotiana tabacum L.). - Acta Societatis Botanicorum Poloniae 84(1): 71-77.

[13] Jiang, Y., Liao, P., van Gestel, N., Sun, Y., Zeng, Y., Huang, S., Zhang, W., van Groenigen, K. J. (2018): Lime application lowers the global warming potential of a double rice cropping system. - Geoderma 325: 1-8.

[14] Karaivazoglou, N. A., Tsotsolis, N. C., Tsadilas, C. D. (2007): Influence of liming and form of nitrogen fertilizer on nutrient uptake, growth, yield, and quality of Virginia (fluecured) tobacco. - Field Crops Research 100: 52-60.

[15] Kochian, L. V., Pineros, M., Liu, J., Magalhaes, J. (2015): Plant adaptation to acid soils: the molecular basis for crop aluminum resistance. - Annual Reviews of Plant Biology 66: 571-598.

[16] Kunhikrishnan, A., Thangarajan, R., Bolan, N. S., Xu, Y., Mandal, S., Gleeson, D. B., Seshadri, B., Zaman, M., Barton, L., Tang, C., Luo, J., Dalal, R., Ding, W., Kirkham, M. B., Naidu, R. (2016): Functional relationships of soil acidification, liming, and greenhouse gas flux. - Advances in Agronomy 139: 1-71.

[17] Li, J., Zhang, M., Lin, Q., Chen, Z., Xie, G., Peng, J., Xiong, D. (2005): Effects of interaction of potassium, calcium and magnesium on flue-cured tobacco growth and nutrient absorption. - Journal of Anhui Agricultural University 32(4): 529-533.

[18] Li, J., Zhang, X., Li, T., Zheng, Z., Wang, Y. (2015): Effect of potash management on potassium absorption and utilization of flue-cured tobacco. - Journal of Plant Nutrition and Fertilizers 21(4): 969-978.

[19] Liao, P., Huang, S., van Gestel, N. C., Zeng, Y. J., Wu, Z. M., van Groenigen, K. J. (2018): Liming and straw retention interact to increase nitrogen uptake and grain yield in a double rice-cropping system. - Field Crops Research 216: 217-224.

[20] Liu, D., Helyar, K. R., Conyers, M. K., Fisher, R., Poile, G. J. (2004): Response of wheat, triticale and barley to lime application in semi-arid soils. - Field Crops Research 90: 287301.

[21] Liu, K., Zhou, J., Li, Q., Wang, M., Li, H., Zhou, W., Wang, R. (2017): Tobacco planting soil of calcium and magnesium content exchange and influence on calcium and magnesium content in tobacco leaves. - Southwest China Journal of Agricultural Sciences 30(9): 2065-2070.

[22] Liu, X., Rezaei Rashti, M., Esfandbod, M., Powell, B., Chen, C. (2018): Liming improves soil microbial growth, but trash blanket placement increases labile carbon and nitrogen availability in a sugarcane soil of subtropical Australia. - Soil Research 56: 235-243.

[23] López-Lefebre, L. R., Rivero, R. M., García, P. C., Sánchez, E., Ruiz, J. M., Romero, L. (2001): Effect of calcium on mineral nutrient uptake and growth of tobacco. - Journal of the Science of Food and Agriculture 81: 1334-1338.

[24] Lynch, J. P., Wojciechowski, T. (2015): Opportunities and challenges in the subsoil: pathways to deeper rooted crops. - Journal of Experimental Botany 66(8): 2199-2210.

[25] Pang, Z., Tayyab, M., Kong, C. B., Hu, C., Zhu, Z., Wei, X., Yuan, Z. (2019): Liming positively modulates microbial community composition and function of sugarcane fields. - Agronomy 9(10): 808.

[26] Qiang, J., Wan, H., Li, F., Wu, S., Xu, S. (2001): Effect of various levels of calium fertilizer on $\mathrm{Ca}$ and $\mathrm{K}$ absorption by flue-cured tobacco. - Journal of Yunnan Agricultural University 2: 120-123.

[27] Qu, Z., Wang, J., Almøy, T., Bakken, L. R. (2013): Excessive use of nitrogen in Chinese agriculture results in high $\mathrm{N}_{2} \mathrm{O} /\left(\mathrm{N}_{2} \mathrm{O}+\mathrm{N}_{2}\right)$ product ratio of denitrification, primarily due to acidification of the soils. - Global Change Biology 20: 1685-1698. 
[28] Shaaban, M., Peng, Q., Lin, S., Wu, Y., Zhao, J., Hu, R. (2014): Nitrous oxide emission from two acidic soils as affected by dolomite application. - Soil Research 52: 841-848.

[29] Shaaban, M., Peng, Q., Hu, R., Wu, Y., Lin, S., Zhao, J. (2015): Dolomite application to acidic soils: a promising option for mitigating $\mathrm{N}_{2} \mathrm{O}$ emissions. - Environmental Science and Pollution Research 22: 19961-19970.

[30] Shao, F., Jiang, C., Zu, C., Xue, B., Xu, J., Shen, J. (2012): Influence of sulfur and stillage fertilizer on the growth, quality of flue-cured tobacco, and $\mathrm{pH}$ in alkaline soil. Acta Botanica Boreali-Occidentalia Sinica 32(12): 2479-2485.

[31] Tang, L., Xiong, D. (2003): Effects of applying lime on the properties of acid soil and the leaves quality in flue-cured tobacco. - Chinese Journal of Eco-Agriculture 11(3): 81-83.

[32] Tang, X., Su, J., He, K., Han, Y., Li, Z., Xie, B., Yang, Q. (2013): Exchangeable Ca and $\mathrm{Mg}$ contents in various purple soils and their effects on $\mathrm{Ca}$ and $\mathrm{Mg}$ contents in flue-cured tobacco. - Chinese Tobacco Science 34(4): 1-4.

[33] Tarin, M. W. K., Fan, L. L., Shen, L., Lai, J. L., Tayyab, M., Sarfraz, R., Chen, L. Y., Ye, J., He, T. Y., Rong, J. D., Chen, L. G., Zheng, Y. S. (2019): Effects of different biochars ammendments on physiochemical properties of soil and root morphological attributes of Fokenia hodginsii (Fujian Cypress). - Applied Ecology and Environmental Research 17(5): 11107-11120.

[34] Wang, H., Li, Y., Hou, J., Huang, J., Liang, W. (2017): Nitrate reductase-mediated nitric oxide production alleviates $\mathrm{Al}$-induced inhibition of root elongation by regulating the ascorbate-glutathione cycle in soybean roots. - Plant and Soil 410: 453-465.

[35] Wei, Z., Shen, F., Wang, L., Fan, D., Yin, Y., Yi, F., Gu, M. (2011): Effects of calcium and magnesium application on uptake, circulation and content of potassium in flue-cured tobacco. - Chinese Tobacco Science 32(40): 66-70.

[36] Xu, Z., Li, Y., Xiao, H., Li, H., Liu, C. (2007): The contents of exchangeable calcium and magnesium in Hunan tobacco-growing soils and their effects on tobacco quality. - Acta Ecologica Sinica 27(11): 4425-4433.

[37] Yan, T., Wang, Y., Lu, D., Liu, X., Zhang, H., Wang, H., Yang, G. (2018): Effects of root-zone potassium fertilizer on the yield, potassium concentration and potassium uptake of flue-cured tobacco. - Soil and Fertilizer Sciences in China 5: 70-76.

[38] Zeng, T., Cai, Z., Wang, X., Liang, W., Zhou, S., Xu, M. (2017): Integrated analysis of liming for increasing crop yield in acidic soils. - Scientia Agricultura Sinica 50(13): 2519-2527.

[39] Zhang, X., Zheng, G. (1987): Effects of continuous liming on crop growth and their absorption of nutrients. - Acta Pedologica Sinica 24(4): 343-350.

[40] Zhang, G., Zhu, Q., Guo, X., Xiang, Z., Wang, S., Shen, S., Ji, X. (2014): Amelioration of dolomite on acidity of flue-cured tobacco soil in south Anhui. - Soils 46(3): 534-538.

[41] Zhang, L., Li, Y., Deng, X., Tian, M., Zheng, M., Zhou, Z., Peng, S., Chen, Z. (2019): Dynamic change of soil $\mathrm{pH}$ and physicochemical properties after application of lime, green manure and biological organic fertilizer. - Acta Tabacaria Sinica 25(3): 60-66.

[42] Zhu, J., Zhang, Y., Liu, Q., Jiang, W., Feng, Y., Liang, Y., Huo, Q., Xia, H., Li, Z. (2016a): Effects of application of lime and potassium humate on flue-cured tobacco yield and quality on newly recovered lands. - Southwest China Journal of Agricultural Sciences 29(2): 346-351.

[43] Zhu, J., Li, Z., Liu, Q., Liang, Y., Huang, C., Huo, Q., Peng, Y., Xia, H., Zhang, Y. (2016b): Influence of lime dosage on soil acidity of acidified yellow soil in renovated flue-cured tobacco field and application effects. - Soil and Fertilizer Sciences in China 3: 43-48.

[44] Zou, W., Xiong, D. (2010): Effects of soil available calcium on some physiological metabolism of flue-cured tobacco. - Journal of Anhui Agricultural University 37(2): 369373. 
[45] Zou, C., Li, Y., Huang, W., Zhao, G., Pu, G., Su, J., Coyne, M. S., Chen, Y., Wang, L., $\mathrm{Hu}, \mathrm{X}$., Jin, Y. (2018): Rotation and manure amendment increase soil macro-aggregates and associated carbon and nitrogen stocks in flue-cured tobacco production. - Geoderma 325: 49-58. 